Abstracta Iranica Abstracta Iranica

Revue bibliographique pour le domaine irano-aryen

Volume 22 | 2001

Comptes rendus des publications de 1999

\title{
Al-Fârâbî and his School. London and New York, Routledge, 1992, 128 p., biblio., index.
}

\section{Christian Jambet}

\section{(2) OpenEdition}

1 Journals

\section{Édition électronique}

URL : http://journals.openedition.org/abstractairanica/36922

DOI : $10.4000 /$ abstractairanica.36922

ISSN : 1961-960X

Éditeur :

CNRS (UMR 7528 Mondes iraniens et indiens), Éditions de l'IFRI

\section{Édition imprimée}

Date de publication : 15 mai 2001

ISSN : 0240-8910

Référence électronique

Christian Jambet, «Al-Fârâbî and his School. London and New York, Routledge, 1992, 128 p., biblio. index. », Abstracta Iranica [En ligne], Volume 22 | 2001, document 421, mis en ligne le 17 février 2010, consulté le 13 octobre 2020. URL : http://journals.openedition.org/abstractairanica/36922 ; DOI : https://doi.org/10.4000/abstractairanica.36922

Ce document a été généré automatiquement le 13 octobre 2020.

Tous droits réservés 


\title{
Al-Fârâbî and his School. London and New York, Routledge, 1992, 128 p., biblio., index.
}

\author{
Christian Jambet
}

1 Il s'agit moins d'une nouvelle étude de la pensée de Fārābī que d'une remarquable enquête portant sur son influence et ses disciples, de sorte qu'est mis en évidence un « âge du farabisme », illustré par Yahyā b. 'Adī, Abū Sulaymān al-Sijistānī, Abu'l-Ḥasan Muhammad al-'Āmirī, Abū Ḥayyān al-Tawhịidī. Belle étude de la culture des cours princières de l'époque, suivie d'une analyse de la doctrine farabienne de la connaissance. L'A. suit les avatars de cette conception de l'intellection dans les structures épistémologiques des penseurs de son École et en souligne l'originalité, qui ne se résume pas en un plat syncrétisme de divers courants de la pensée grecque, et conduit à des théories du salut. Pour ne citer que deux exemples, l'A. montre que l'illumination intellective, selon Sijistānī, a des conséquences morales et politiques (p. 68) et que, pour Fārābī et pour Yahyā b. 'Adī, «la logique constitue l'une des clés vitales du salut et, ainsi, du Paradis lui-même. » (p. 56). Guide bibliographique utile.

\section{INDEX}

Thèmes : 9. Philosophie 
AUTEURS

CHRISTIAN JAMBET

Paris 